\title{
Analysis of shear mechanical properties of corrugated steel web lining concrete composite beam
}

\author{
Chen Cheng ${ }^{1, ~ a ~, B i n g ~} \mathrm{Li}^{2, \mathrm{~b}}$, Wen zhou Wang ${ }^{2, \mathrm{c}}$, Fu lin Yang ${ }^{2, \mathrm{~d}}$ \\ ${ }^{1}$ School of Transportation, Southeast University, Nanjing, Jiangsu, 210096, China \\ ${ }^{2}$ Guangdong Nanyue Transportation Investment \& Construction Co. Ltd, Guangzhou, Guangdong, \\ 516000, China \\ akevas@163.com, b124186934@qq.com, cwangwz67@126.com, d275505041@qq.com
}

Keywords:Concrete composite beams with corrugated steel webs; Shear performance; Lining concrete

Abstract. The structure of composite beam A and composite beam B is formed by the combination of corrugated steel web plate and lining concrete. A finite element model was established to study the distribution between steel plate and lining concrete in elastic stage, and to analyze the failure process of interface between concrete and steel plate.

\section{Introduction}

Corrugated steel web lining concrete composite beam is mainly used in the structure of prestressed concrete composite box girder bridge with corrugated steel webs. In the corrugated steel web and concrete transition section, the composite beam ${ }^{[1]}$ is used to smooth transfer of shear stress, and to relaxed local stress. The mechanical properties of composite beam is complex, so the shear force distribution and other mechanical properties should be studied.

A finite element model was established in the software of ABAQUS. Elastic-plastic damage model was used to simulated mechanical properties of concrete. By calculation of the finite element model, the shear ratio of concrete and steel plate in the same section is obtained, and the failure mode of composite beam is presented.

\section{Structure of composite beam}

The concrete grade is C50 for the composite beam. Support of the composite beam is at the bottom of two ends, and load of the composite is at the top of middle span. Overall structure of composite beam is shown in Fig.1.

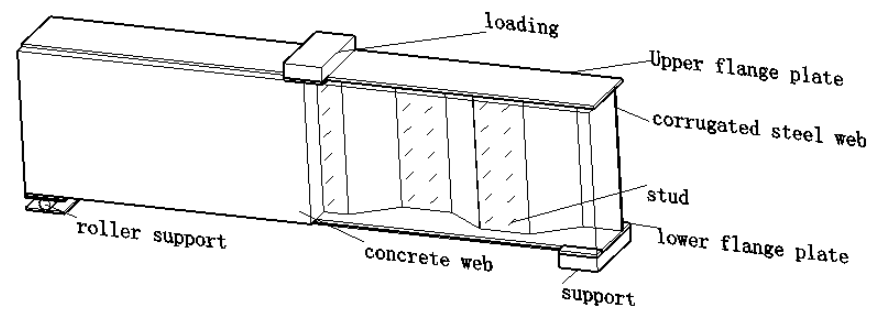

Fig. 1 Overall structure of composite beam

The detailed structure of composite beam A is shown in Fig.2. The structure of corrugated steel web and layout of the stud is as shown in Fig2-1. As shown in Fig2-2, at the peak steel web, the thickness of concrete is $200 \mathrm{~mm}$; at the trough steel web, thickness of concrete is $400 \mathrm{~mm}$. The thickness of corrugated steel web is $10 \mathrm{~mm}$, and the upper and lower plate thickness is $18 \mathrm{~mm}$. The length of composite beam is $3.78 \mathrm{~m}$, and the height of composite beam is $970 \mathrm{~mm}$. The diameter of stud is $16 \mathrm{~mm}$, and the length of stud is $120 \mathrm{~mm}$. The diameter of stud cap is $28 \mathrm{~mm}$. The reinforcement plan of composite beam A is shown in Fig.2-3. 

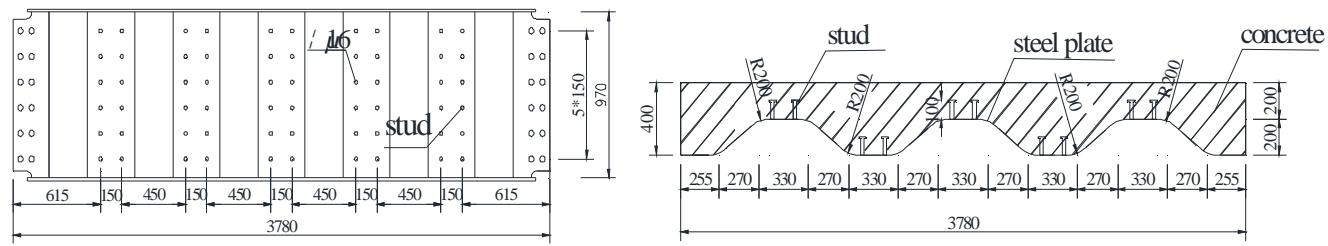

Fig.2-1 Structure of corrugated steel web Fig.2-2 Plane of web

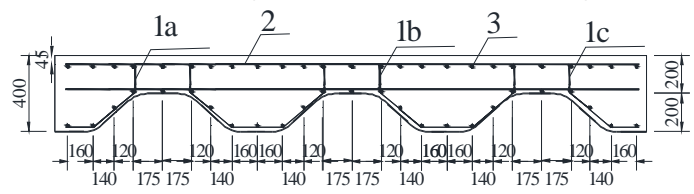

Fig.2-3 Plane of Reinforcement

Fig.2 Structure diagram of composite beam A

The detailed structure of composite beam B is shown in Fig.3. As shown in Fig3-1, for composite beam B, at the peak steel web, the thickness of concrete is $400 \mathrm{~mm}$; at the trough steel web, thickness of concrete is $600 \mathrm{~mm}$. The other size of structure for composite beam B is same as the composite beam A. The reinforcement plan of composite beam B is shown in Fig.3-2. The diameter of reinforcement for composite beam A and composite beam B is $8 \mathrm{~mm}$.

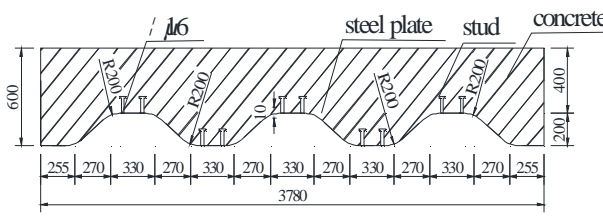

Fig.3-1 Plane of web

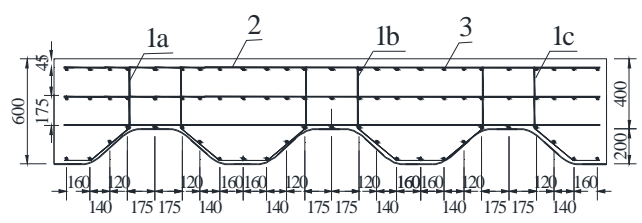

Fig.3-2 Plane of Reinforcement

Fig.3 Stucture diagram of composite beam B

\section{Constitutive model of material}

The FEA software of ABAQUS was used to establish the finite element model of composite beam mentioned above. In this model, the constitutive relationship model of uniaxial tension and uniaxial compression constitutive, which is for concrete, is selected from the formula of $\operatorname{Code}^{[2]}$ for Concrete Structure Design (GB 50010-2010).

The three broken line plastic strengthened constitutive model ${ }^{[3-4]}$ is adopted for steel plate, and the classical von Mises yield criterion is adopted for its strength criterion. The stress-strain relationship is:

$$
\sigma_{i}= \begin{cases}E_{s} \varepsilon_{i} & \left(\varepsilon_{i} \leq \varepsilon_{y}\right) \\ f_{y}+0.01 E_{s}\left(\varepsilon_{i}-\varepsilon_{y}\right) & \left(\varepsilon_{y}<\varepsilon_{i} \leq \varepsilon_{u}\right) \\ f_{u}=1.2 f_{y} & \left(\varepsilon_{i}>\varepsilon_{y}\right)\end{cases}
$$

Where, $\sigma \mathrm{i}$ is the equivalent stress of steel material; fy is the yield strength of steel material; fu is the ultimate strength of steel material. fu /fy is between 1.2 and 1.3, and take the bottom value 1.2. Es is the elastic model for steel material, and the value of Es $2.1 \times 105 \mathrm{MPa}$; $\varepsilon \mathrm{i}$ is the equivalent strain of steel material, and $\varepsilon y$ is the yield strain of steel material.

The ideal elastic-plastic model ${ }^{[3-4]}$ is adopted for reinforcement. The stress-strain relationship is:

$$
\sigma_{i}=\left\{\begin{array}{cc}
E_{s} \varepsilon_{i} & \left(\varepsilon_{i} \leq \varepsilon_{y}\right) \\
f_{y} & \left(\varepsilon_{i}>\varepsilon_{y}\right)
\end{array}\right.
$$

Where, Es is the elastic model for reinforcement, and the value of Es $2.1 \times 105 \mathrm{MPa}$; $\varepsilon$ i is the equivalent strain of steel material, and $\varepsilon y$ is the yield strain of steel material. 


\section{Element type and mesh generation}

3D linear reduced integration element(C3D8R) was used to simulate corrugated steel web, concrete and studs. Linear beam element(B31) was used to simulate reinforcement. The division of element grid is shown in Fig.4.
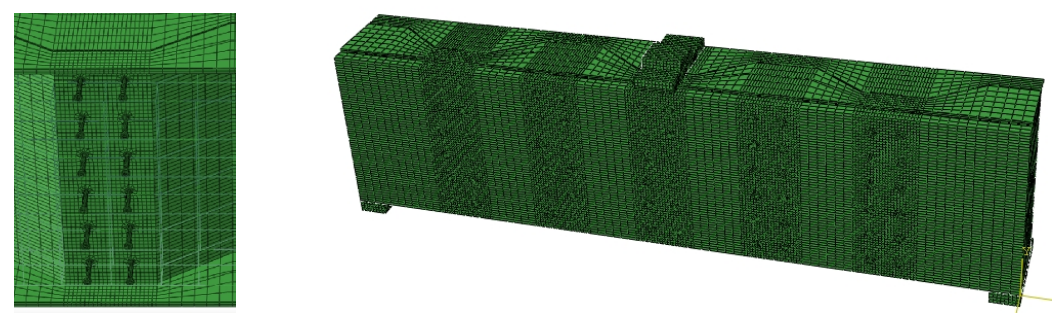

Fig.4-1 Mesh division of local model Fig.4-2 Mesh division of the whole model

Fig.4 Division of element grid

\section{Interface simulation}

In the finite element model, the interfaction between the top plate of the steel plate and concrete, and the interfaction between bottom plate and concrete, is simulated by the common nodes method. The interfaction between corrugated steel web plate, stud and concrete web is simulated by the contact pairs. Reinforcement is embedded in concrete, and the slip between reinforcement and concrete is not considered.

\section{Boundary conditions and loading method}

At the left side bottom of the composite beam, X, Y, Z directions constraints are applied. At the right side bottom of the composite beam, $\mathrm{Y}, \mathrm{Z}$ directions constraints are applied. Displacement load is applied at the middle of the span. The nonlinear problem is solved by iterative method.

\section{Shear distribution anslysis}

As shown in Fig.5, four sections are selected to calculate the shear distribution for concrete and steel plate.

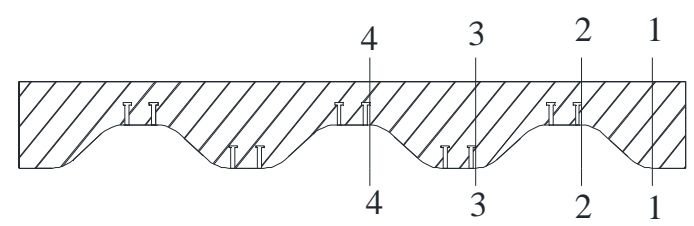

Fig.5 Calculation section for shear distribution

Applied load is as horizontal axis, shear force sharing ratio for concrete and steel plate is as vertical axis. Shear force sharing for beam A is shown Fig.6 and Fig.7. As shown in Fig.6, for beam A, in the elastic distinct, shear force sharing of steel plate and concrete is approximately constant. 

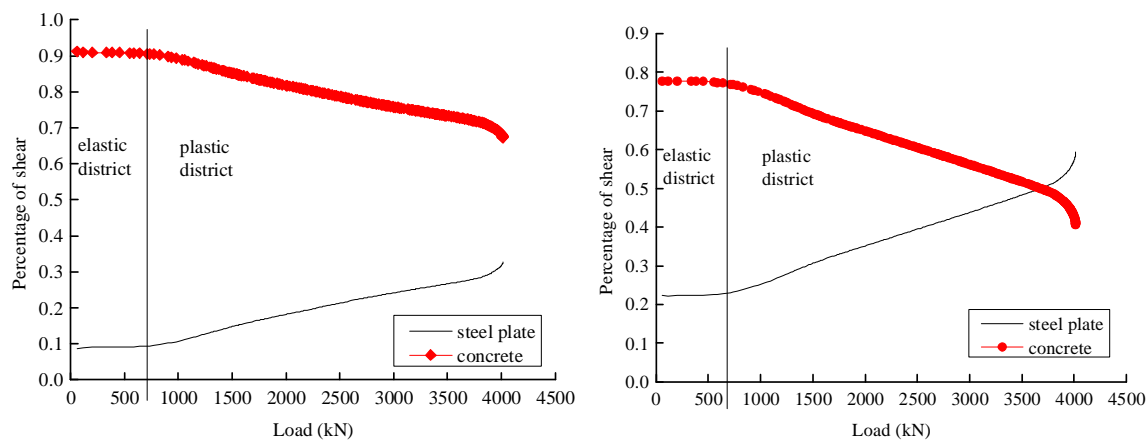

Fig.6-1 Shear force sharing for section 1-1 Fig.6-2 Shear force sharing for section 2-2
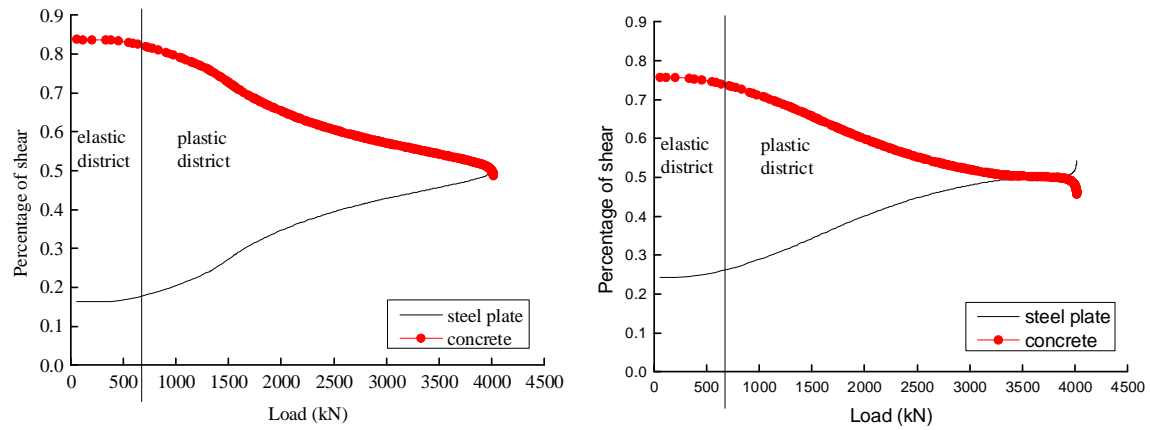

Fig.6-3 Shear force sharing for section 3-3 Fig.6-4 Shear force sharing for section4-4

Fig.6 Shear force sharing for beam A

Also, as shown in Fig.7, for beam B, in the elastic distinct, shear force sharing of steel plate and concrete is approximately constant.
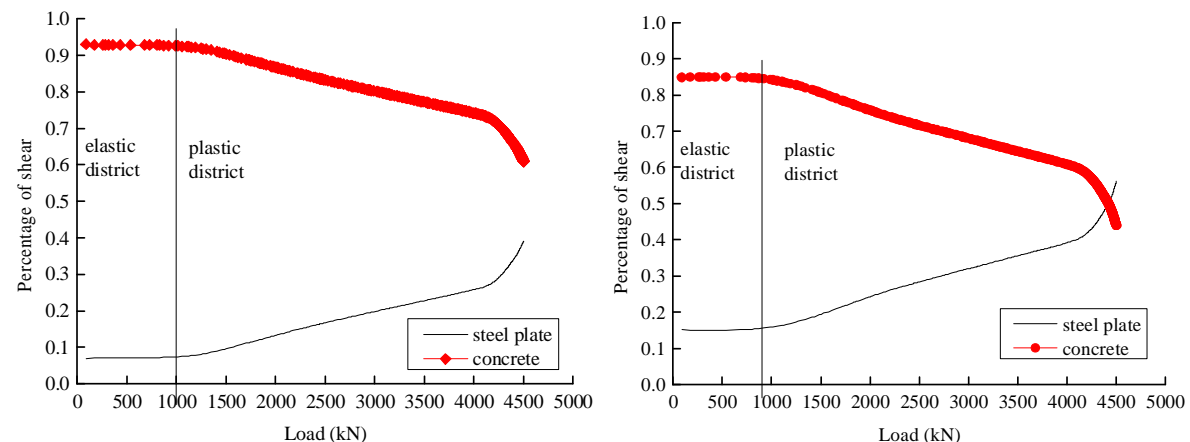

Fig.7-1 Shear force sharing for section 1-1 Fig.7-2 Shear force sharing for section 2-2
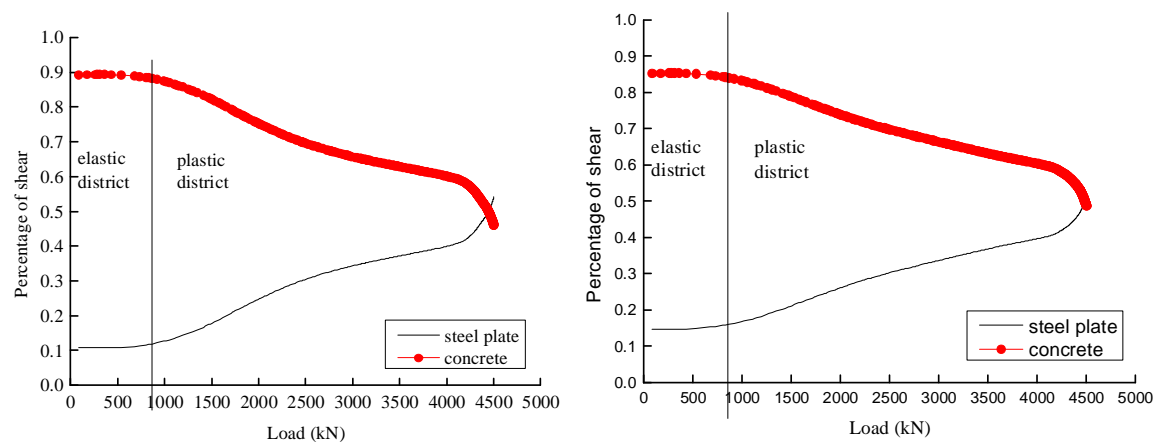

Fig.7-3 Shear force sharing for section 3-3 Fig.7-4 Shear force sharing for section 4-4

Fig.7 Shear force sharing for beam B 
In the $\operatorname{Code}^{[5]}$ for design of prestressed concrete box girder bridge with corrugated steel webs(DB41/T643-2010), formula of shear distribution for lining concrete was put forward. The formula is as follows:

$$
V_{\mathrm{cd}}=\frac{G_{\mathrm{c}} \cdot A_{\mathrm{c}}}{G_{\mathrm{c}} \cdot A_{\mathrm{c}}+G \cdot A_{\mathrm{s}}} \cdot V_{\mathrm{d}}
$$

Where, $V_{\mathrm{cd}}$ is the design shear force value of lining concrete; $G_{\mathrm{c}}$ is shear modulus of lining concrete; $A_{\mathrm{c}}$ is the average section area of lining concrete; $G$ is effective shear modulus of corrugated steel webs; $A \mathrm{~s}$ is effective section area of corrugated steel webs; $V_{\mathrm{d}}$ is the design vertical shear force of corrugated steel webs.

By the finite element model and formula(3), the shear force ratio of steel plate and concrete can be obtained. The comparison of shear ratio obtained by the two methods is shown in Table.1.

Table 1 comparison of shear distribution

\begin{tabular}{ccccccc}
\hline section & \multicolumn{3}{c}{ Beam-A } & \multicolumn{3}{c}{ Beam-B } \\
\hline & FEA & $\mathrm{f}$ & FEA/f & FEA & $\mathrm{f}$ & FEA/f \\
\hline $1-1$ & 0.906 & 0.876 & 1.034 & 0.925 & 0.914 & 1.012 \\
$2-2$ & 0.770 & 0.783 & 0.983 & 0.841 & 0.877 & 0.959 \\
$3-3$ & 0.824 & 0.876 & 0.941 & 0.876 & 0.914 & 0.958 \\
$4-4$ & 0.741 & 0.783 & 0.946 & 0.836 & 0.877 & 0.953 \\
\hline
\end{tabular}

Note:FEA is the shear force ratio obtained by the finite element model, and $\mathrm{f}$ is the shear force ratio obtained by the formula(3).

From table 1, it's clear that the shear force ratio obtained the finite element model is in good agreement with that of formula(3), which verifies the correctness of the formula in the Code(DB41/T643-2010).

\section{Failure process of interface between concrete and steel plate and analysis}

From the finite element model, the vertical shear force of all studs for circular cross root section, and the vertical shear force of interface for the interface between concrete and corrugated steel web can be calculated. As shown in Fig.8, for beam A and beam B, when it was at the elastic district, the vertical shear force value of studs is very small, and the vertical shear force value of interface is linearly increased. When it was at the plastic district, the vertical shear force of interface is not linearly increased, and the vertical shear force of studs increased.
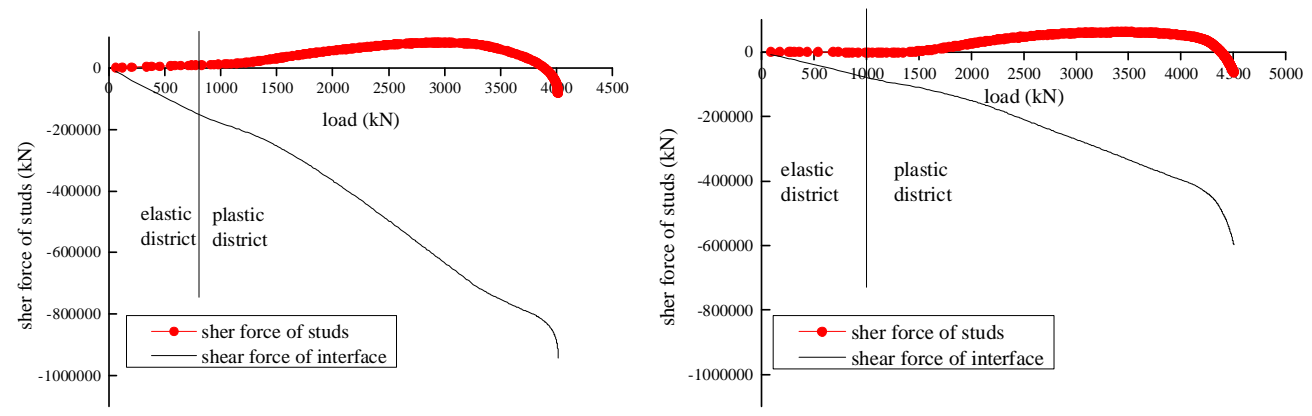

Fig. 8-1 Shear forces for beam A Fig.8-2 Shear forces for beam B

Fig. 8 Vertical shear forces of studs and interface

The failure mode of interface between concrete and steel plate is when the vertical shear force of interface linearly increased, the vertical shear force of studs is very small, and the vertical shear force sharing of steel plate and concrete is approximately constant. When the interface between concrete and corrugated steel web is damaged, the vertical shear force of all studs increased, and the vertical shear force sharing of steel plate and concrete is no longer approximately constant. 


\section{Conclusions}

By the finite element analysis, it is proved that for corrugated steel web lining concrete composite beam, at the elastic stage the shear force on the same section is distributed according to the equibalent shear stiffness. Furthermore, it's proved that the formula of the shear distribution for composite beam is correct.

The failure mode of interface between concrete and steel plate is that when the interface between concrete and corrugated steel web is damaged, the shear force of all studs increased, and the shear force sharing of steel plate and concrete is no longer approximately constant.

\section{References}

[1] Yue sheng Jiang. Shear checking calculation of steel-concrete composite section for PC box-gieder bridge with corrugated steel webs[J]. Highway,2013,12,p.91-96. (in Chinese)

[2] Ministry of Housing and Urban-Rural Development of the Peoples's Republic of China. Code for design of concrete structures (GB 50010-2010) [S]. Beijing: China Architecture \& Building Press, 2010 .

[3] Ding Faxing, Ni Ming, Gong Yongzhi, et al. Experimental study on slip behabior and calculation of shear bearing capacity for shear stud connectors[J]. Journal of Building Structures, 2014,35(9):98-106. (in Chinese)

[4] Jian guo Nie. Experiment, Theory and Application of Steel Concrete composite beams[M]. Beijin: Science Press, 2005.

[5] Henan Bureau of Quality and Technical Supervision. Code for Design of the pretressed Concrete Box-gird Highway Bridge with Corrugated Steel Webs (DB41/T643-2010) [S]. Beiging:China Communications Press, 2010. 